\title{
Mapeamento de qualidade em pastagens do Cerrado por meio de imagens Sentinel 2
}

\author{
Mapping the Cerrado pasture quality by using Sentinel 2 images
}

\author{
Brenda Nogueira de BritoI, Jorge Luís Silva Brito II
}

\section{RESUMO}

Os mapeamentos de evolução do uso da terra são cada vez mais difundidos e relevantes no âmbito da Ciência da Informação Geográfica. Mapear as pastagens e, sobretudo, a qualidade das pastagens do Cerrado, exige o desenvolvimento de abordagens computacionais e dados precisos. Nessa perspectiva, este estudo tem por objetivo aprimorar técnicas de mapeamento de qualidade em pastagens. Para tanto, foram utilizados dados do Satélite Sentinel 2, sensor MSI, e calculada a média do Índice de Vegetação da Diferença Normalizada (NDVI) de um conjunto de 4 imagens, ao longo das estações do ano, e realizada comparação com dados de campo. De acordo com os resultados obtidos, foi possível identificar 3 níveis de degradação: "Moderado", "Baixo" e "Nenhum". Valores de NDVI < 0,37 indicam pastagens moderadamente degradadas, aqueles correspondentes ao intervalo entre 0,37 e 0,43 podem ser considerados com nível de degradação "Baixo" e valores de NDVI > 0,43 representam pastagens não degradadas. Ao utilizar os intervalos para mapear a qualidade das pastagens da Sub-bacia Hidrográfica do Ribeirão Douradinho, obteve-se uma acurácia muito boa, correspondente ao İ́ndice Kappa de 0,72.

Palavras-chave: Cerrado; NDVI; Qualidade em pastagens; Sentinel 2

\section{ABSTRACT}

Mappings of land use evolution are increasingly widespread and relevant in the context of Geographic Information Science. Mapping pasture, especially, the quality of it in the Cerrado, requires the development of computational approaches and accurate data. From this perspective, the current study aimed to improve the mapping of quality pastures techniques. To that end, we used data from the Sentinel 2 Satellite and MSI sensor, and calculated the average of the Normalized Difference Vegetation Index (NDVI), from a set of 4 images, along the seasons of the year, and compared them with field data as well. According to the results, it was possible to identify 3 levels of degradation: "Moderate", "Low" and "None". NDVI values of 0.37 indicate moderately degraded pastures; those corresponding to the interval between 0.37 and 0.43 can be considered as having a "Low" degradation level and 0.43 indices represent not degraded pastures. By using the intervals for mapping the quality of pastures in the Ribeirão Douradinho River basin, we identified a very good accuracy, corresponding to the Kappa Index of 0.72 .

Keywords: Cerrado; NDVI; Pasture Quality; Sentinel 2

\section{INTRODUÇÃO}

Mapear dinâmicas de uso e cobertura da terra no Cerrado torna-se um desafio, na medida em que ele ocupa a posição de segundo maior bioma brasileiro em

\footnotetext{
I Bacharel em Geografia, com mestrado em andamento em Geografia pela Universidade Federal de Uberlândia, Uberlândia, Minas Gerais. E-mail jbrito@ufu.br. ORCID: https://orcid.org/0000-0001-7703-2308

II Professor titular no departamento de geografia da Universidade Federal de Uberlândia, Uberlândia, Minas Gerais. E-mail brendanogueirageo@gmail.com. ORCID: https://orcid.org/0000-0002-9884-3289
} 
extensão territorial (mais de 2 milhões de $\mathrm{km}^{2}$ ). Além disso, a baixa disponibilidade de imagens livres de nuvens e a alta sazonalidade climática dificultam o mapeamento baseado em imagens de satélite (SANO et al., 2019). No entanto, a necessidade de elaboração de mapas precisos para o bioma fez surgir projetos com metodologias diversificadas e comprometidas com a qualidade espacial e temporal dos resultados. O primeiro desses foi o Projeto de Conservação e Extração Sustentável da Diversidade Biológica Brasileira - Probio, de 2002 (SANO et al., 2008). A metodologia e os produtos do Probio serviram de base para outros mapeamentos, como o Projeto de Mapeamento do Uso e Cobertura do Cerrado (Projeto Terra Class Cerrado) de 2013 (INPE, 2013). Os dados do Terra Class Cerrado revelam que a área ocupada com pastagem em 2013, no Bioma Cerrado, era de $600.840 \mathrm{Km}^{2}$, correspondendo a 29 \% da área do bioma (Scaramuzza, 2017).

Os mapeamentos de pastagens e, sobretudo, de qualidade de pastagens são recentes no Cerrado. Para todo o bioma, foi elaborado em 2018 o "Mapa da Degradação de Pastagens no Cerrado", a partir da análise de série temporal de imagens MODIS/NDVI (pixel de 250m) de 2001 a 2017 (PEREIRA et al., 2018). De acordo com os autores, cerca de $39 \%$ das pastagens do Cerrado estão degradadas, perfazendo uma área de mais de 18 milhões de hectares (PEREIRA et al., 2018).

A degradação de pastagens é entendida como um processo evolutivo de perda de vigor, produtividade, e capacidade de recuperação natural, tornando-as susceptíveis aos efeitos nocivos de pragas, doenças e plantas invasoras, culminando com a degradação avançada dos recursos naturais em razão de manejos inadequados (MACEDO; ZIMMER, 1993). Um grave impacto associado a degradação de pastagens é a alteração climática, decorrente da diminuição de matéria orgânica do solo e biomassa do pasto, entre outros. Em contrapartida, o manejo adequado do pasto tem alto potencial em mitigar este impacto, por sua capacidade de "sequestrar carbono" (DIAS FILHO, 2011).

A definição de critérios para a avaliação do estágio de degradação das pastagens cultivadas é tarefa difícil, tanto em vista a diversidade das espécies quanto em relação às características morfológicas e dos ecossistemas em que são cultivadas. Neste sentido, estudos têm demonstrado o potencial do uso de imagens de satélite associadas aos índices de vegetação para a caracterização, discriminação e estudo da 
porcentagem de cobertura verde e biomassa de pastagens cultivadas no bioma Cerrado (FERREIRA et al., 2012; ANJOS et al., 2013; BRITO et al., 2018).

Conforme apontado por Parente e Ferreira (2018), grande parte dos erros de omissão (pastagens não identificadas) em mapas de pastagens que utilizam sensores de resolução espacial baixa estão relacionados ao tamanho do pixel, que impossibilita a separação de várias classes em uma área reduzida. Nesta perspectiva, o uso de imagens Sentinel 2 (pixel de $10 \mathrm{~m}$ ) se constitui em alternativa viável para aumentar a acurácia dos produtos.

Diversos estudos de monitoramento da vegetação vêm sendo realizados, em todo o mundo, a partir de imagens Sentinel 2. Addabbo et al. (2016) utilizaram esses dados para avaliar a saúde da vegetação nos arredores do Palácio de Caserta (Itália). Ao comparar os resultados de NDVI do Sentinel com os do Landsat 8, concluíram que, para áreas de estudo menores, os dados do Sentinel são mais adequados (ADDABBO et al., 2016). Além dessa, já foram realizadas pesquisas sobre: o uso do sensor para mapeamento do potencial de intensificação sustentável da agricultura brasileira (KUCHLER et al., 2017); relações das fitofisionomias de Caatinga com atributos dos solos (SILVEIRA, 2018); identificação de áreas com plantas invasoras em Unidades de Conservação (GOMES, 2017), entre outros.

Nos estudos da pastagem, Punalekar, et al. (2018) provaram que a missão Sentinel 2 tem alto potencial para mapear a dinâmica de biomassa presente no pasto, uma vez calculado o Índice de Área Foliar - LAI/NDVI para as bandas de 10 metros de resolução. Ao comparar os resultados obtidos de processamento digital com os medidos em campo (reflectância da copa, LAI e altura do dossel), observaram que as imagens do sensor MSI podem ser usadas para monitorar gramíneas e produtividade em pastagens no sul da Inglaterra. Lugassi et al. (2019), utilizaram Índices de Vegetação de imagens Sentinel 2 para mapear a qualidade ecológica de pastagens em Israel, comparando com análises laboratoriais de proteína bruta e fibra detergente neutra presentes no pasto. Concluíram que há um alto potencial de uso de imagens Sentinel 2 nesses estudos e que são necessárias mais pesquisas em áreas de estudo distribuídas por todas as regiões geográficas. Verifica-se assim, que os dados obtidos pelo processamento de imagens Sentinel podem ser aplicados para 0 monitoramento de pastagens, nos mais diversos ambientes da Terra. 
Desta forma, busca-se identificar métricas para o mapeamento de qualidade das pastagens do Cerrado, indicando o seu grau de degradação, com base em índices de vegetação, utilizando como área de estudo a Sub-bacia Hidrográfica do Ribeirão Douradinho. Nessa perspectiva, inicia-se o texto a partir dos materiais e métodos da pesquisa, apresentando a área de estudo e os processamentos realizados. Em seguida, são descritos os resultados obtidos em relação à área de estudo selecionada, em conjunto com as discussões, culminando nas considerações finais.

\section{MATERIAIS E MÉTODOS}

Os mapas e o processamento das imagens foram executados no software QGIS versão 3.4. Para o mapeamento das pastagens foram utilizadas as imagens do sensor MSI (MultiSpectral Instrument - MSI) da missão Sentinel-2. Esta missão, composta por dois satélites de monitoramento da Terra (A e B), teve início em 2015, com o lançamento do primeiro satélite - Sentinel 2 A. Em 2017 foi lançado o segundo satélite - Sentinel 2 B - cobrindo, então, toda a superfície do planeta. Sincronizados com o sol, os satélites circulam em órbita polar, ambos na mesma órbita, permitindo resoluções temporais entre 5 e 10 dias, a depender das latitudes da área de interesse. A resolução espacial varia entre 10, 20 e 60 metros, de acordo com as bandas espectrais, que somam 13 (quadro 1). A resolução radiométrica é de 12 bits, ou seja, 4.096 tons de cinza (ESA, 2020).

\section{Quadro 1 - Características das bandas dos Satélites Sentinel 2 - MSI}

\begin{tabular}{|c|c|c|c|c|}
\hline $\begin{array}{l}\text { Número da } \\
\text { banda }\end{array}$ & Nome da banda & \multicolumn{2}{|c|}{$\begin{array}{l}\text { Comprimento de } \\
\text { onda central }\end{array}$} & $\begin{array}{c}\text { Resolução } \\
\text { espacial }\end{array}$ \\
\hline 1 & Aerossóis & 442.7 & 442.2 & 60 metros \\
\hline 2 & Azul & 492.4 & 492.1 & 10 metros \\
\hline 3 & Verde & 559.8 & 559.0 & 10 metros \\
\hline 4 & Vermelho & 664.6 & 664.9 & 10 metros \\
\hline 5 & Red Edge & 704.1 & 703.8 & 20 metros \\
\hline 6 & Red Edge & 740.5 & 739.1 & 20 metros \\
\hline 7 & Red Edge & 782.8 & 779.7 & 20 metros \\
\hline 8 & Infravermelho Próximo (NIR) & 832.8 & 832.9 & 10 metros \\
\hline $8 \mathrm{~A}$ & Red Edge & 864.7 & 864.0 & 20 metros \\
\hline 9 & Vapor de Água & 945.1 & 943.2 & 60 metros \\
\hline 10 & Cirros & 1373.5 & 1376.9 & 60 metros \\
\hline 11 & Infravermelho de Onda Curta (SWIR) & 1613.7 & 1610.4 & 20 metros \\
\hline 12 & Infravermelho de Onda Curta (SWIR) & 2202.4 & 2185.7 & 20 metros \\
\hline
\end{tabular}

Fonte: ESA (2020). 
Fruto da colaboração entre a Agência Espacial Europeia (European Space Agency - ESA), a Comunidade Europeia e empresas da iniciativa privada, a missão Sentinel 2 revolucionou o monitoramento ambiental da Terra, ao disponibilizar imagens gratuitas de toda a superfície do planeta com resolução espacial de 10 metros no espectro visível da Radiação Eletromagnética - REM. Por sua vez, a resolução temporal moderada viabiliza estudos com séries temporais ao longo de todo o período fenológico da planta (ESA, 2020).

\section{1 Área de estudo}

A Sub-bacia Hidrográfica do Ribeirão Douradinho, com cerca de $920 \mathrm{~km}^{2}$, tem como rio principal o Ribeirão Douradinho, afluente do Rio Tijuco - tributário do Rio Paranaíba/Paraná. Seu principal afluente (margem esquerda) é o Ribeirão Panga. Em termos geopolíticos, está localizada na Região Geográfica Imediata de Uberlândia, entre os municípios de Uberlândia e Monte Alegre de Minas, no Estado de Minas Gerais e as principais rodovias que a cruzam são a BR-497 e a MG-455 (figura 1).

Figura 1 - Localização da Sub-bacia Hidrográfica do Ribeirão Douradinho

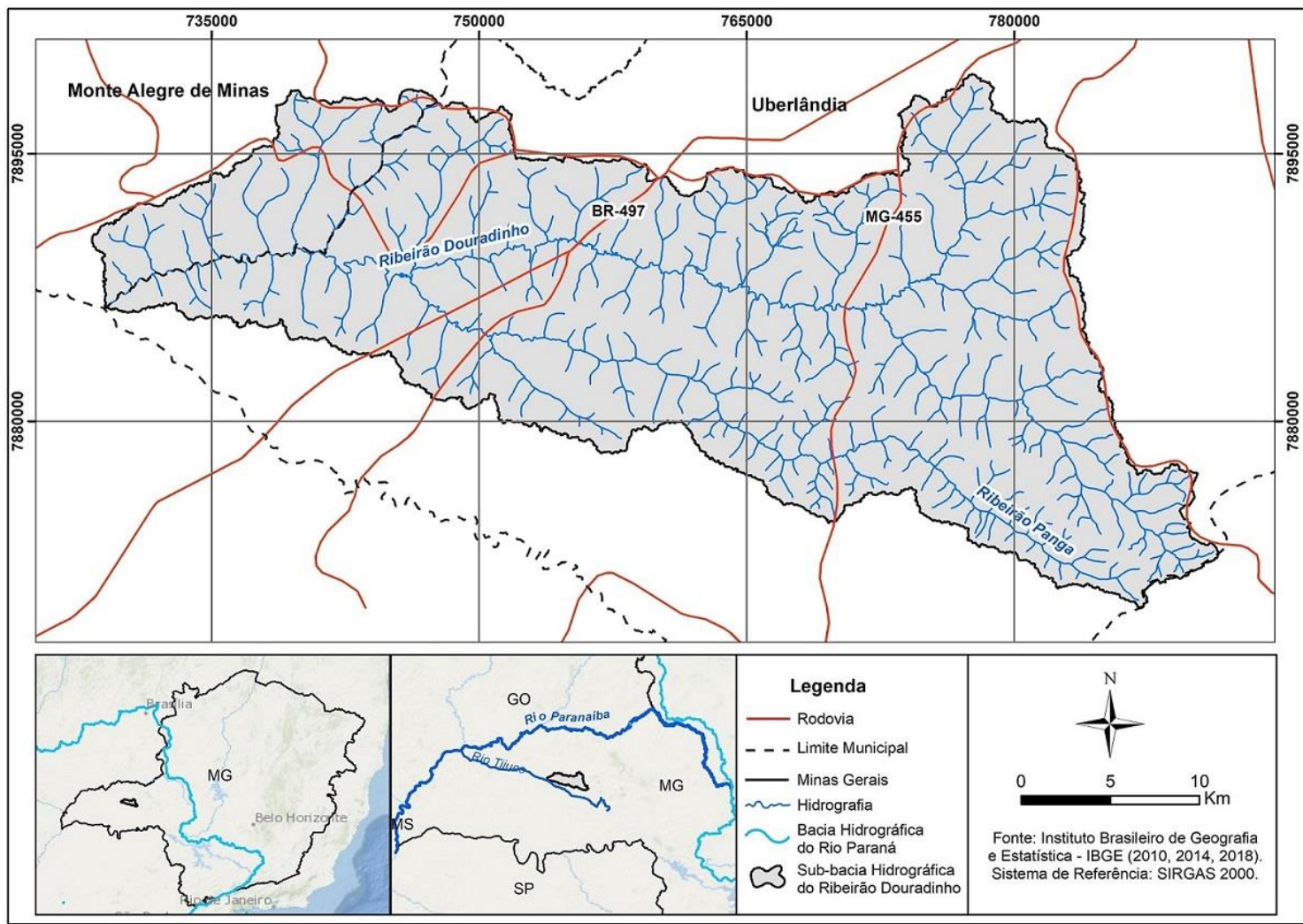

Fonte: IBGE $(2010 ; 2014 ; 2018)$. 
De acordo com Rosa (1995) a Sub-bacia do Ribeirão Douradinho está localizada na Bacia Sedimentar do Paraná, onde a litologia predominante é composta por veios de quartzo, quartzitos e lateritas. O relevo é, em grande parte, dissecado com "vertentes suaves, ocasionalmente interrompidas por ruptura de declive estrutural [...], aparecendo intensos processos erosivos, tais como ravinas e voçorocas" (ROSA, 1995, p. 61). O clima é do tipo Aw (Classificação de Koppen), com inverno seco (de maio a setembro), verão chuvoso (outubro a março), temperatura média anual de 22 ${ }^{\circ} \mathrm{C}$ e precipitação anual de aproximadamente $1.500 \mathrm{~mm}$ (figura 2).

\section{Figura 2 - Climograma do Município de Uberlândia, do ano de 2018}

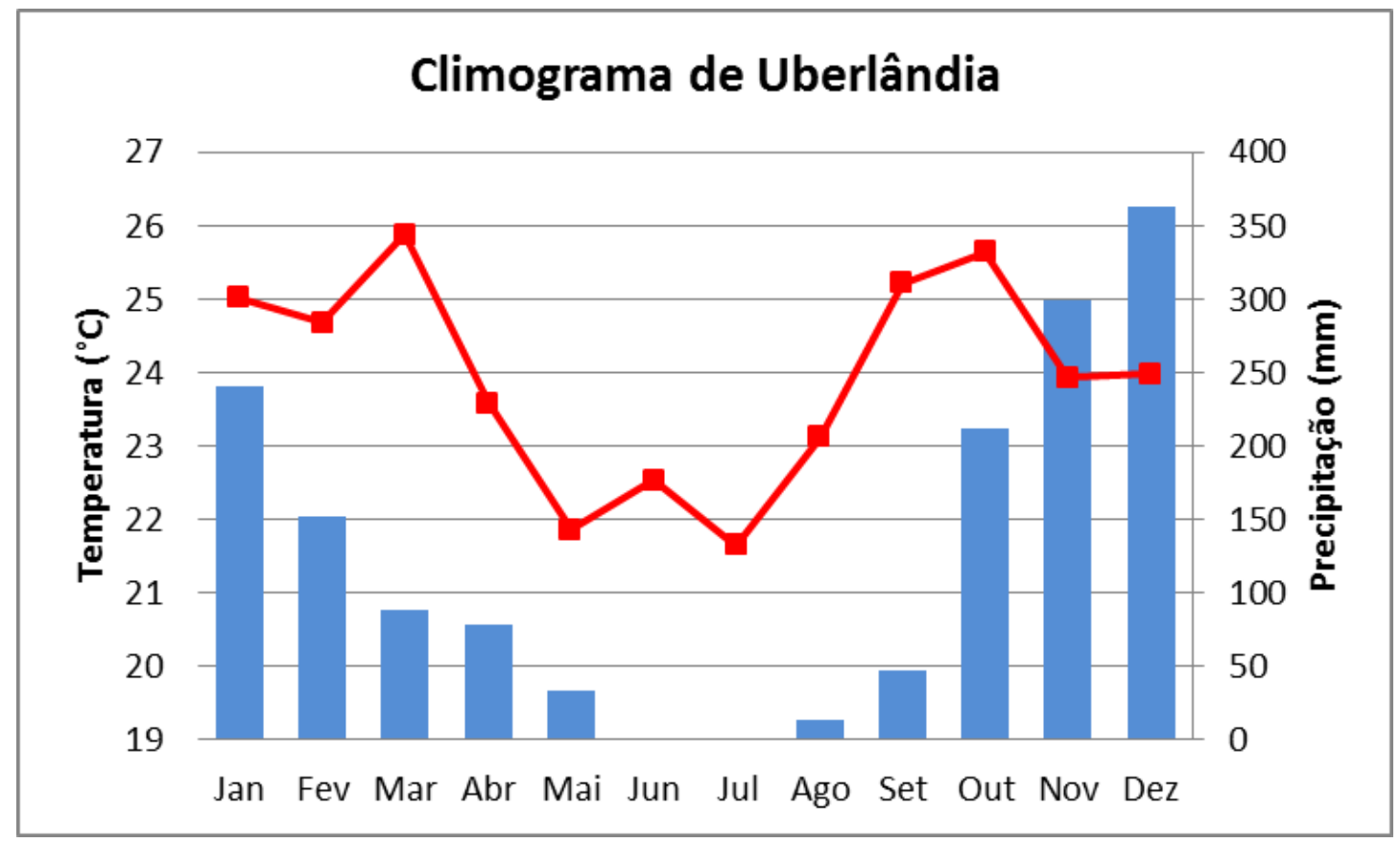

Fonte: Adaptado de INMET, 2018.

Ademais, está localizada, integralmente, no Bioma Cerrado, embora intensamente antropizada, comportando Latossolos (98\%) e Solos Hidromórficos (2\%), com forte presença de material arenoso (ROSA, 1995). De acordo com Baccaro (1990), na área da bacia do Ribeirão Douradinho os fortes aguaceiros do período chuvoso provocam um carreamento muito forte dos materiais superficiais, predominantemente arenosos, muito friáveis, resultando em intensos processos de escoamento pluvial, com formação de sulcos, ravinas e voçorocas e o arrasto laminar do horizonte superficial dos solos. 


\subsection{0 Índice de Vegetação da Diferença Normalizada}

Assim como as demais dimensões da natureza e aquelas criadas pelo homem, a vegetação porta características singulares que se materializam em um comportamento espectral único, passível de identificação por sensores remotos. 0 incremento de técnicas robustas de processamento digital de imagens possibilita diversas abordagens para o monitoramento de fenômenos vegetativos (como o stress hídrico), dentre as quais figuram os Índices de Vegetação (IV).

Com o propósito principal de identificar a presença ou ausência de vegetação, esses índices são calculados através de fórmulas matemáticas, que podem incluir razão, adição, subtração e multiplicação de bandas espectrais. As bandas mais utilizadas nos monitoramentos com IV são as do Vermelho e Infravermelho Próximo (Near Infrared - NIR). Isso ocorre por que a vegetação absorve radiação solar na faixa do visível da Radiação Eletromagnética (REM) e reflete na faixa do NIR (LIU, 2007).

Criado por Rouse et al. (1973), o Índice de Vegetação da Diferença Normalizada (Normalized Difference Vegetation Index - NDVI) é uma das ferramentas mais utilizadas para estudo de vigor vegetativo em pastagens (FERREIRA et al., 2012; ANJOS et al., 2013; BRITO et al., 2018). Os valores de NDVI variam entre -1 e 1, considerando o -1 como solo exposto e/ou ausência total de vegetação. Já os valores acima de 0 são indicativos de presença de vegetação, com aumento de biomassa ao se aproximarem de 1 (LIU, 2007).

\subsection{Processamento dos dados}

O mapeamento de qualidade das pastagens foi obtido por meio da correspondência entre a média dos valores de índices de vegetação NDVI (Eq. 1) e polígonos de pastagens classificados em campo, seguindo oito etapas:

1) Download de imagens Sentinel 2 na plataforma "Copernicus", da Agência Espacial Europeia (ver https://scihub.copernicus.eu/dhus/\#/home). A cena correspondente à área de estudo é a 22KGD. São necessárias duas imagens de cada data para cobrir a bacia toda, uma do Sentinel 2 A e uma do Sentinel 2 B, formando quatro mosaicos (imagens). Os produtos baixados são do Nível $1 \mathrm{C}$ - 
Reflectância de Topo da Atmosfera (Top of Atmosphere - TOA). A resolução espacial das bandas utilizadas $(3,4$ e 8$)$ é de 10 metros.

2) Correção atmosférica - transformação das imagens de TOA para Reflectância de Superfície (Bottom of Atmosphere - BOA) - no software SNAP, por meio da ferramenta "Sen2cor", da ESA.

3) Obtenção da média do NDVI (Eq. 1) para uma coleção de quatro imagens de satélite (Sentinel 2 A-B/MSI) de um ano (abril, julho e outubro de 2018 e janeiro de 2019), dada por (Liu, 2007):

$$
\text { Média }(\mathrm{NDVl})=\Sigma_{\mathrm{n}}\left(\frac{\rho_{\mathrm{NIR}}-P_{\mathrm{RED}}}{\mathrm{P}_{\mathrm{NIR}}+\mathrm{P}_{\mathrm{RED}}}\right) / \mathrm{n}
$$

Em que

$\mathrm{n}$ = número de imagens obtidas no período de um ano (4 imagens);

$\rho_{\text {NIR }}=$ reflectância na banda do vermelho (banda 4 do sensor MSI/Sentinel 2)

$\rho_{\text {RED }}=$ reflectância na banda do infravermelho próximo (banda 8 do sensor MSI/Sentinel 2).

Nessa etapa foi utilizado o software "QGIS", versão 3.4, para realizar a álgebra de mapas, por meio da "Calculadora Raster".

4) Mapeamento das pastagens pelo método de classificação supervisionada de imagens Sentinel 2 (MSI), de janeiro de 2019, composição RGB/483, utilizando o plugin "Dzetsaka", configurado com o Modelo de Mistura Gaussiano (Gaussian Mixture Mode), disponível no software QGIS. Posteriormente, foi realizada inspeção visual para edição dos polígonos mapeados (dados Sentinel 2 e Google Earth Pro).

5) Trabalho de campo realizado em 5 de julho de 2019 (período da estação seca) na Sub-bacia Hidrográfica do Ribeirão Douradinho, para identificação do grau de degradação de 26 polígonos de pastagens (quadro 2).

\section{Quadro 2 - Níveis de degradação de pastagens segundo os parâmetros limitantes}

\begin{tabular}{|cc|}
\hline Níveis de Degradação & Parâmetros Limitantes \\
\hline Nenhum & Pastagens melhoradas com alto vigor e boa qualidade. \\
Baixo & Médio a baixo vigor, qualidade e baixa população. \\
Moderado & Baixo vigor, qualidade e baixa população, associado com a presença de plantas \\
invasoras, cupins e/ou solo descoberto.
\end{tabular}

Fonte: Adaptado de SPAIN e GUALDRÓN (1988); BRASIL (2015). 
6) Análise de correspondência entre os valores da média de NDVI e tipo de pastagem dos polígonos classificados em campo ( 9 polígonos selecionados dentre os 26 amostrados), definindo os intervalos de NDVI para os três níveis de degradação de pastagens.

7) Fatiamento da imagem para conversão de valores médios de NDVI em classes de níveis de degradação de pastagem na área da Sub-bacia Hidrográfica do Ribeirão Douradinho, para geração do mapa de qualidade das pastagens.

8) A verificação da acurácia do mapa ocorreu com base no cálculo da Concordância Total (Po) (Eq. 2) e do Índice Kappa ( $k$ ) (Eq. 3).

$$
\begin{aligned}
& P o=\frac{\sum x_{i}}{N} \\
& k=\frac{P_{o}-P_{c}}{1-P_{c}}
\end{aligned}
$$

Em que

$\Sigma X i=$ somatório da diagonal principal da matriz de confusão;

$N=$ número total de observações (17 polígonos de campo);

$P C=$ soma do produto dos elementos da matriz dividido por $N^{2}$ (ROSA, 2007).

\section{RESULTADOS E DISCUSSÕES}

O mapa da figura 3 mostra a espacialização das áreas ocupadas com pastagens em 2019, na Sub-bacia Hidrográfica do Ribeirão Douradinho, totalizando 302,16 km² de pastagens, correspondendo a aproximadamente 33\% da área de estudo. Observase a predominância dessa classe de uso da terra na porção centro-norte da Sub-bacia e nas áreas mais próximas aos cursos d'água principais, que englobam terrenos de declividade superior e maior disponibilidade hídrica natural. 
Figura 3 - Mapa de áreas ocupadas com pastagem na Sub-bacia Hidrográfica do Ribeirão Douradinho, no ano de 2019

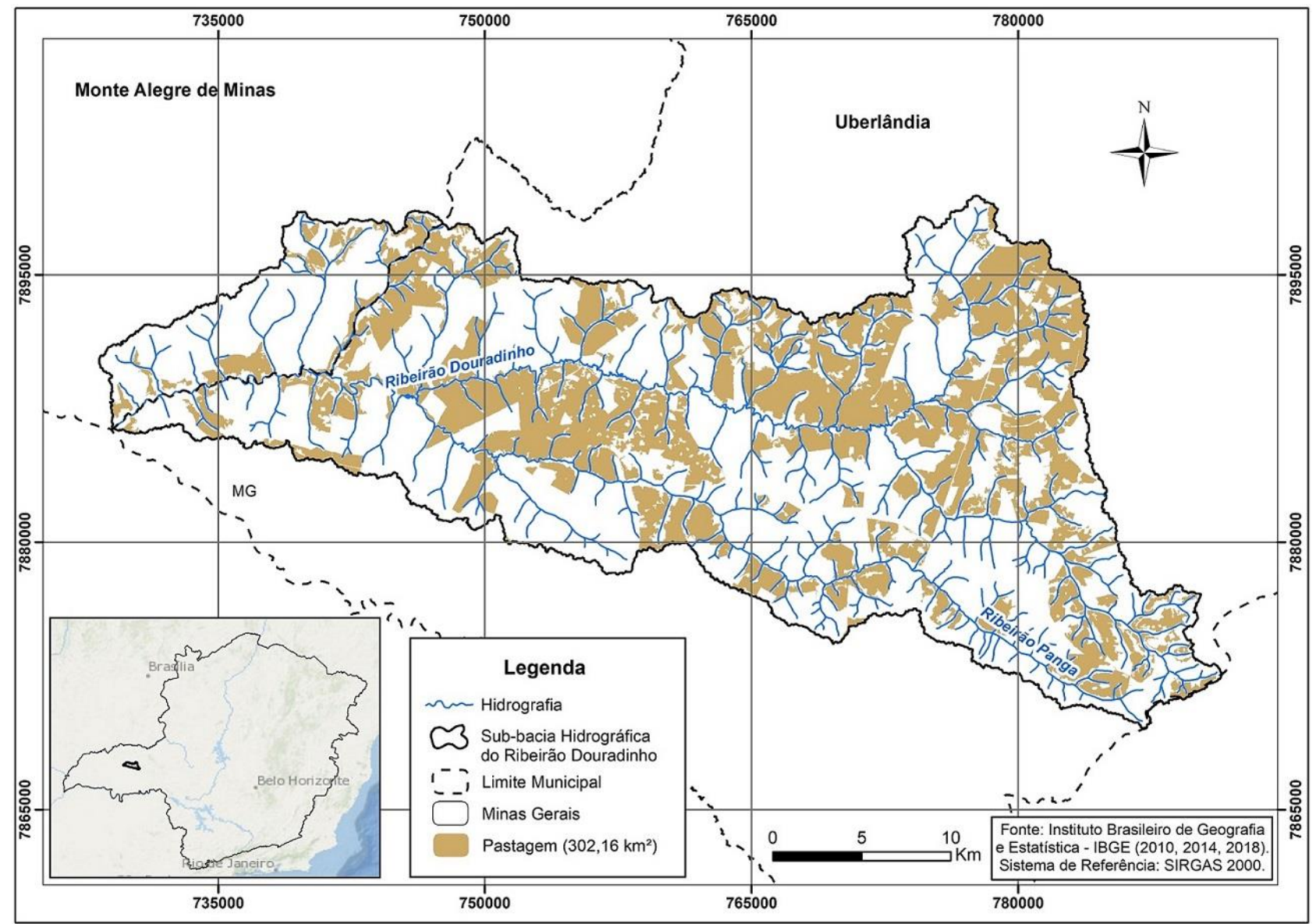

Fonte: Organização dos autores, 2020.

A figura 4 mostra a distribuição espacial dos valores de NDVI para As pastagens da Sub-Bacia do Ribeirão Douradinho, variando de -0,13 a 0,96 entre as 4 datas. Os valores de NDVI indicam o vigor vegetativo das pastagens, sendo que, de acordo com o esperado, os menores vigores vegetativos (NDVI igual a $-0,13$ e 0,06) foram registrados no meio e final da estação seca, nos meses de julho e outubro, respectivamente. Os valores de NDVI da estação chuvosa (abril e janeiro) representam vigores vegetativos expressivamente mais elevados, com valores mínimos superiores a 0,10. A média dos quatro valores de NDVI (meio e fim da estação chuvosa e meio e fim da estação seca) é um bom indicador do vigor vegetativo médio anual das pastagens da área de estudo, que varia entre 0,21 e 0,84 . 
Figura 4 - NDVIs da área de estudo ao longo das estações seca e chuvosa, com destaque para a região do Assentamento Nova Tangará

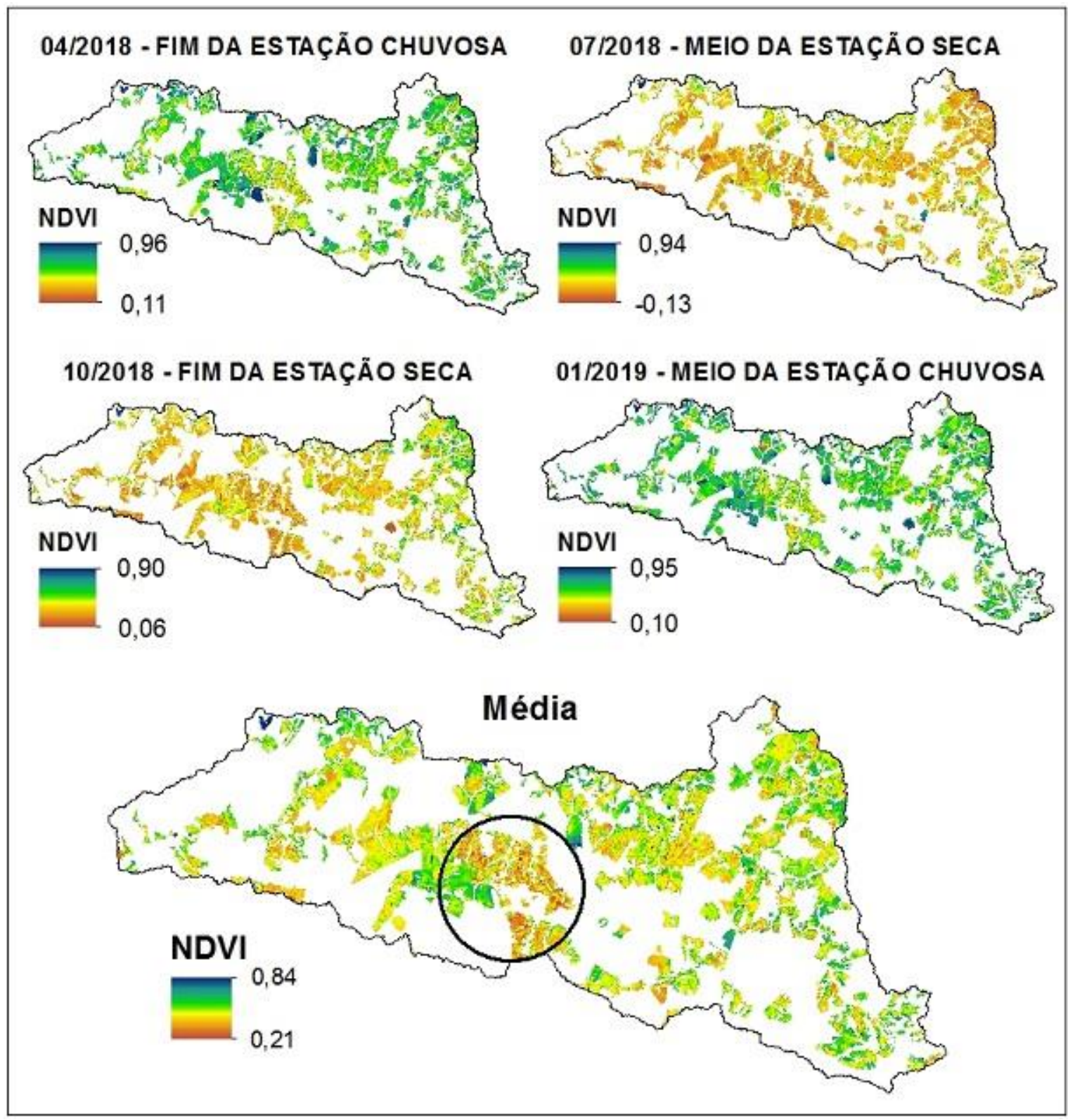

Fonte: ESA (2018; 2019). Organização dos autores, 2020.

Diante dos resultados apresentados, nota-se uma dinâmica de mudanças no vigor vegetativo ao longo das estações e dos períodos de colheita/manejo das atividades agrícolas temporárias, com destaque para a porção oeste da Sub-bacia. Observam-se, ainda, valores baixos de vigor vegetativo na área do Assentamento Nova Tangará, indicado na figura 4 com um círculo. Uma provável causa dos índices baixos nesse local consiste na disponibilidade hídrica deficiente na região, com a presença de solos arenosos, associada a conflitos pela água, constatada por Garcia (2014), além da presença de pastagens degradadas. 
No quadro 3 apresenta-se as coordenadas centrais de polígonos de pastagem visitados em campo durante a estação seca (julho de 2019), com a identificação do nível de degradação da pastagem e etapa do estudo em que foram utilizados (durante o mapeamento ou na verificação de acurácia). Cabe ressaltar que, foram selecionados pontos mais representativos de cada classe, obtendo-se o quantitativo final de 26 amostras, sendo 11 de degradação "moderada", 9 "baixa" e 6 "nenhuma".

Quadro 3 - Coordenadas dos pontos de pastagens visitados em campo, seu nível de degradação e a etapa dos estudo em que eles foram utilizados

\begin{tabular}{|ccccc|}
\hline Ponto & Coordenada X & Coordenada Y & Degradação do pasto & Etapa de utilização \\
\hline 1 & 779487.52 & 7891847.25 & Moderada & Verificação de acurácia \\
2 & 779487.19 & 7892290.84 & Baixa & Verificação de acurácia \\
3 & 778756.56 & 7889535.00 & Nenhuma & Mapeamento \\
4 & 778414.52 & 7889078.51 & Baixa & Verificação de acurácia \\
6 & 777265.30 & 7883893.19 & Baixa & Mapeamento \\
7 & 775671.98 & 7881657.16 & Nenhuma & Mapeamento \\
9 & 771151.72 & 7875627.37 & Baixa & Verificação de acurácia \\
10 & 770399.70 & 7877058.59 & Moderada & Verificação de acurácia \\
11 & 770415.29 & 7877948.91 & Moderada & Mapeamento \\
12 & 769982.67 & 7879275.13 & Moderada & Verificação de acurácia \\
13 & 770584.84 & 7882206.92 & Baixa & Mapeamento \\
14 & 767192,66 & 7881890,39 & Baixa & Verificação de acurácia \\
17 & 763673.32 & 7889186.20 & Nenhuma & Verificação de acurácia \\
19 & 766957.59 & 7892915.86 & Baixa & Verificação de acurácia \\
20 & 765403.10 & 7893642.36 & Moderada & Verificação de acurácia \\
22 & 756215.43 & 7890659.73 & Nenhuma & Verificação de acurácia \\
24 & 744512.51 & 7887073.77 & Nenhuma & Verificação de acurácia \\
28 & 749767.34 & 7887066.32 & Baixa & Mapeamento \\
29 & 750728.32 & 7887500.83 & Baixa & Verificação de acurácia \\
30 & 752159.05 & 7886333.58 & Nenhuma & Mapeamento \\
31 & 756209.82 & 7889300.59 & Moderada & Mapeamento \\
32 & 757571.29 & 7888926.67 & Moderada & Verificação de acurácia \\
33 & 758338.86 & 7888375.19 & Moderada & Verificação de acurácia \\
34 & 756965.33 & 7887195.72 & Moderada & Mapeamento \\
36 & 769011.41 & 7892566.24 & Moderada & Verificação de acurácia \\
37 & 772858.46 & 7893803.05 & Moderada & Verificação de acurácia \\
\hline
\end{tabular}

Fonte: Organização dos autores, 2019.

Os resultados de vigor vegetativo derivado das imagens Sentinel 2, associados às amostras de degradação do pasto, obtidas em campo, e as imagens em composição colorida são coerentes entre si, conforme observado no quadro 4. Notase que as pastagens com NDVI mais elevados (verdes) relacionam-se com maior presença de vegetação (cores mais associadas ao ciano) na composição RGB/483. Da mesma forma, o solo exposto, com resposta espectral mais associada ao magenta na composição colorida, incorre em valores de NDVI mais baixos (laranja/vermelho). 
Quadro 4 - Resposta espectral de imagens Sentinel/MSI/R4G8B3, com seus respectivos NDVIs médios e fotografias, para os polígonos de pastagem visitados em campo, considerando os níveis de degradação das pastagens

\begin{tabular}{|c|c|c|c|c|c|}
\hline $\begin{array}{c}\text { Nível de } \\
\text { Degradação da } \\
\text { pastagem }\end{array}$ & Ponto & $\begin{array}{l}\text { Imagem } \\
\text { Sentinel } 2\end{array}$ & NDVI (Média) & Fotografia & $\begin{array}{c}\text { Intervalo de NDVI médio } \\
\text { do pasto/Descrição de } \\
\text { campo }\end{array}$ \\
\hline \multirow{6}{*}{ Não degradado } & \multirow[b]{2}{*}{3} & & & \multirow[t]{2}{*}{ 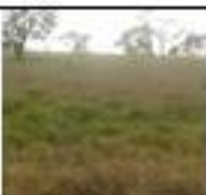 } & Média NDVI: 0,46 \\
\hline & & & & & $\begin{array}{l}\text { O pasto apresenta } \\
\text { vegetação com vigor de } \\
\text { médio a alto. }\end{array}$ \\
\hline & \multirow[b]{2}{*}{7} & & & & Média NDVI: 0,49 \\
\hline & & & & & $\begin{array}{l}\text { O pasto apresenta } \\
\text { vegetação com vigor de } \\
\text { médio a alto. }\end{array}$ \\
\hline & & & & & Média NDVI: 0,44 \\
\hline & 30 & & & & $\begin{array}{l}\text { Pasto apresentando alto } \\
\text { vigorvegetativo. }\end{array}$ \\
\hline \multirow{6}{*}{$\begin{array}{c}\text { Levemente } \\
\text { degradado (baixo) }\end{array}$} & \multirow[b]{2}{*}{6} & & & & Média NDVI: 0,38 \\
\hline & & & & & $\begin{array}{l}\text { Pasto visivelmente } \\
\text { manejado, porém, com } \\
\text { médio vigor. }\end{array}$ \\
\hline & \multirow[b]{2}{*}{13} & & & & Média NDVI: 0,39 \\
\hline & & & & & $\begin{array}{l}\text { Vigor mediano e sem } \\
\text { registro de população. }\end{array}$ \\
\hline & \multirow[b]{2}{*}{28} & & & & Média NDVI: 0,39 \\
\hline & & & & & $\begin{array}{l}\text { Pasto predominantemente } \\
\text { com médio vigor. }\end{array}$ \\
\hline \multirow{6}{*}{$\begin{array}{l}\text { Moderadamente } \\
\text { degradado }\end{array}$} & \multirow[b]{2}{*}{11} & & & & Média NDVI: 0,32 \\
\hline & & & & & $\begin{array}{l}\text { Pasto com baixo vigor e } \\
\text { presença de cupins. }\end{array}$ \\
\hline & \multirow[b]{2}{*}{31} & & & \multirow{2}{*}{ 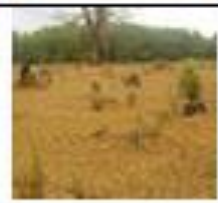 } & Média NDVI: 0,33 \\
\hline & & & & & $\begin{array}{l}\text { Baixo vigor, presença de } \\
\text { espécies invasoras e tocos } \\
\text { de silvicultura. }\end{array}$ \\
\hline & \multirow[b]{2}{*}{34} & & & & Média NDVI: 0,30 \\
\hline & & & & & $\begin{array}{l}\text { Pasto com baixo vigor, } \\
\text { apresentando solo exposto. }\end{array}$ \\
\hline
\end{tabular}

Fonte: ESA/Sentinel 2, 2018-2019. Organização dos autores, 2019. 
A partir dos valores de NDVI médios de polígonos amostrados em campo ( 9 amostras, conforme o quadro 4), foram definidas as 3 classes de nível de degradação. Esses intervalos foram utilizados para classificar a imagem com os valores médios de NDVI de 2018/2019 das pastagens, resultando no Mapa de Qualidade de pastagens (figura 5).

Figura 5 - - Mapa de qualidade em pastagens da Sub-bacia Hidrográfica do Ribeirão Douradinho, com exemplos dos três tipos de pasto mapeados

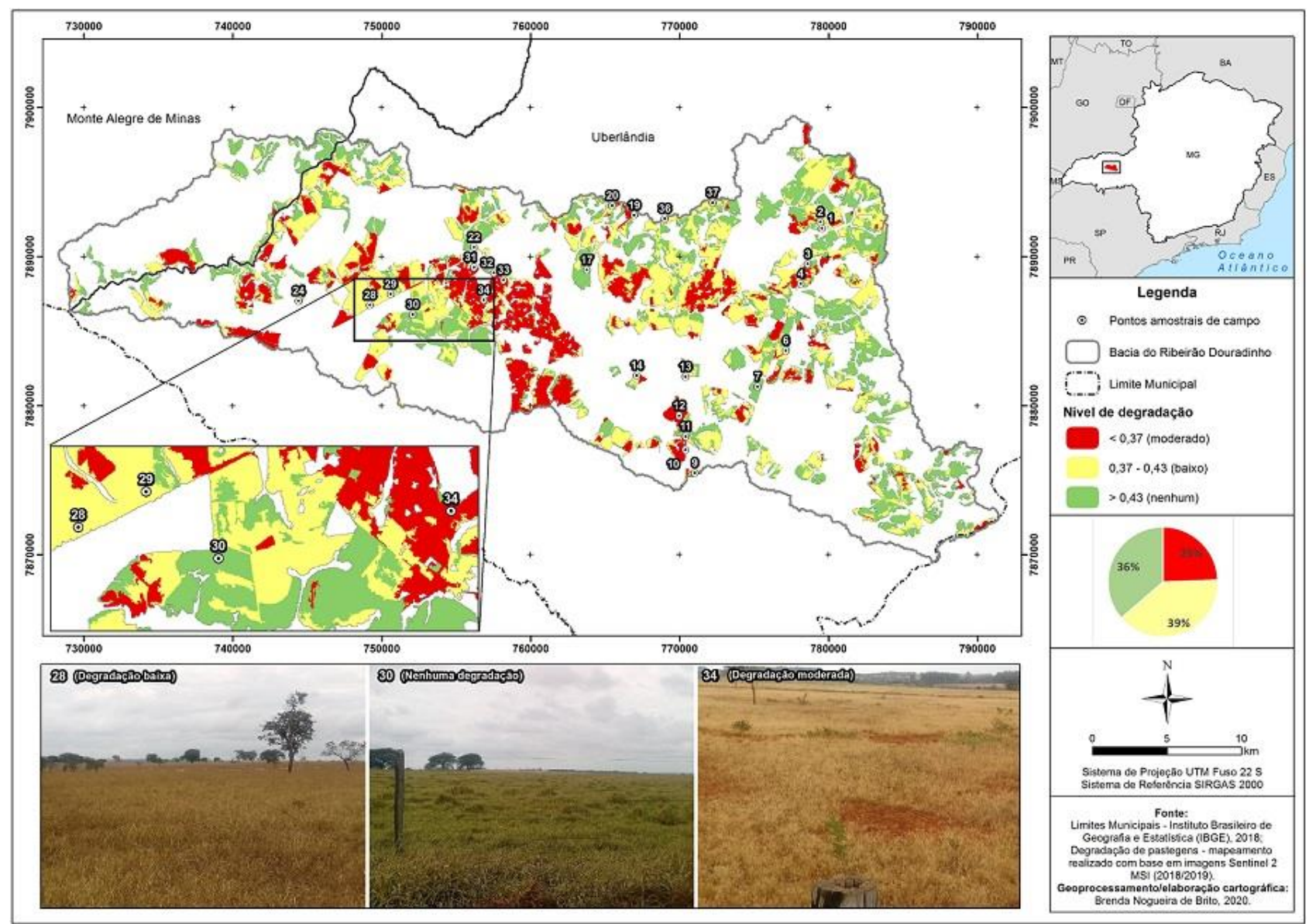

Fonte: ESA/Sentinel 2, 2019. Organização dos autores, 2019.

O mapa da figura 5 mostra que os níveis de degradação "baixo" e "nenhum", representados nas cores amarela e verde claro respectivamente, são predominantes na Sub-bacia. Já as pastagens classificadas com nível de degradação "moderado" (cor vermelha), são mais expressivas na região do Assentamento Nova Tangará, evidenciando forte correlação entre os valores de NDVI, a realidade constatada em campo e as dinâmicas socioambientais apresentadas pela literatura (DIAS, 2014). É importante ressaltar que todo o território da área de estudo é classificado pelo 
Instituto Mineiro de Gestão das Águas (IGAM) como "área de conflito por uso de recursos hídricos". Ao todo são quatro áreas registradas na Sub-bacia por meio de Declaração de Área de Conflito (DAC), sendo a área correspondente ao Assentamento registrada sob a DAC 003/2011 (IGAM, 2019). A tabela 1 indica a área ocupada no ano de 2019 para os 3 níveis de degradação de pastagem da Sub-Bacia do Ribeirão Douradinho.

Tabela 1 - Área ocupada por classe de nível de degradação das pastagens da Sub-Bacia Hidrográfica do Ribeirão Douradinho em 2019

\begin{tabular}{|c|c|c|c|}
\hline \multirow{2}{*}{ Nível de Degradação } & \multirow{2}{*}{ Valores médios de NDVI } & \multicolumn{2}{|c|}{ Área Ocupada } \\
\hline & & $\left(\mathrm{Km}^{2}\right)$ & $(\%)$ \\
\hline Moderado & $<0,37$ & 73,70 & 24,40 \\
\hline Baixo & 0,37 a 0,43 & 118,76 & 39,30 \\
\hline Nenhum & $>0,43$ & 109,70 & 36,30 \\
\hline & & 302,16 & 100 \\
\hline
\end{tabular}

Fonte: Organização dos autores, 2020.

Conforme mostrado na tabela 1 , os níveis "moderado" e "baixo", que apresentam vigores vegetativos abaixo de 0,43, perfazem $63,70 \%$ das áreas de pastagens na Sub-bacia. Em contrapartida, 36,30\% da área de estudo apesenta pastagens melhoradas, sem indícios de degradação. Esses resultados concordam com os mapeamentos de degradação e níveis de degradação em pastagens, realizados para o Cerrado (PEREIRA, et al. 2018) e para o Triângulo Mineiro (BRITO, et al. 2018b), respectivamente, indicam razoável acurácia dos valores encontrados. Brito et al. (2018b), concluíram que aproximadamente $30 \%$ das pastagens do Triângulo são de boa qualidade e, portanto, não degradadas. Ao passo que as pastagens consideradas de moderadamente a fortemente degradadas perfazem 33\% da área total de pasto - dados próximos aos encontrados na área de estudo. Pereira et al. (2018), ao realizar mapeamento de pastagens degradadas, identificaram que na Região do Triângulo Mineiro não existem quantidades significativas de degradação, como aquelas constatadas no norte do estado.

Deve-se considerar, ainda, os resultados obtidos por Brito et al. (2018) que, ao comparar dados coletados em campo com valores de NDVI, encontraram forte correlação entre a sazonalidade climática da região do Cerrado com os percentuais de biomassa verde (\%CV) em pastagens. De acordo com os autores, durante os meses 
mais secos a maior parte do Bioma apresenta valores de \%CV entre 40 e 50\%. Cabe ressaltar, que os atributos dos solos, sobretudo a textura, exerce forte influência nas respostas espectrais dos solos, devendo ser amenizados em estudos posteriores (BRITO, e al. 2018).

Por outro lado, avaliações mais precisas podem ser garantidas com 0 incremento de estatísticas, tais como a Concordância Total (ou Exatidão Global) e o Índice Kappa - métodos recorrentes para medir acurácia de mapeamentos de uso e cobertura da terra. Ambos os coeficientes são realizados por meio de matriz de confusão, embora a concordância total considere apenas os valores da diagonal principal e o Índice Kappa englobe a matriz como um todo (ROSA, 2007). Os resultados obtidos neste estudo estão expressos na tabela 2.

Tabela 2 - Matriz de confusão com os resultados de Concordância Total (Po) e Índice Kappa(k) com base em 17 pontos de referência

\begin{tabular}{cccccc}
\cline { 3 - 5 } & & \multicolumn{3}{c}{ Mapa temático } \\
\cline { 3 - 6 } Nerdade terrestre de degradação & Moderado & Baixo & Nenhum & Total \\
\cline { 3 - 6 } & Moderado & 8 & 0 & 0 & 8 \\
& Baixo & 2 & 3 & 1 & 6 \\
& Nenhum & 0 & 0 & 3 & 3 \\
& Soma & 10 & 3 & 4 & $\mathbf{1 7}$ \\
\hline
\end{tabular}

Fonte: Adaptado de Rosa (2007).

Verifica-se, na tabela 2, que o mapeamento atingiu a Exatidão Global de 0,82 e o Índice Kappa de 0,72. Este, compreendido no intervalo entre 0,6 e 0,8, é considerado como de qualidade "muito boa". Para garantir a excelência dos mapeamentos de qualidade em pastagens, indica-se a continuidade nos estudos dessa natureza, acrescentando na metodologia outros índices de vegetação e mais pontos de campo, para a medida mais eficaz da precisão e acurácia do mapeamento.

A partir da análise dos resultados apresentados, acredita-se que seja possível aplicar os intervalos classificados para os níveis de degradação em pastagens em todo o Cerrado, uma vez que a área de estudo compreende um mosaico de formações campestres e savânicas, além de comportar florestas estacionais e solos distróficos (SCHIAVINI; ARAÚJO, 1989; OLIVEIRA, 2011), comuns em diversas unidades de paisagem do Bioma (AB' SÁBER, 2003; SILVA, et al. 2006). 
Além disso, a possibilidade de processamento de dados em nuvem, amparada pelo advento da plataforma Google Earth Engine - GEE, permite análises geoespaciais com índices de vegetação, em regiões de grandes extensões territoriais e em diversas datas, por meio de imagens com correção atmosférica. Cabe ressaltar que, atualmente, estão disponíveis na plataforma GEE imagens Sentinel 2 de nível 1C (reflectância de topo da atmosfera) a partir de 2015 e de nível 2A (reflectância de superfície com pré-processamento com a ferramenta "Sen2cor" da ESA) a partir de 2017 (GOOGLE LLC, 2020).

\section{CONSIDERAÇÕES FINAIS}

Elaborar métricas para o mapeamento de qualidade em pastagens é de grande relevância em um país com forte tradição agropecuária, marcado por atividades de apropriação dos recursos naturais, muitas vezes, improdutivas. Identificar áreas com pastagens degradadas pode ser útil, tanto para os pecuaristas que desejam aumentar sua produtividade, quanto para o Estado, ao elaborar políticas públicas mais eficientes no que concerne à recuperação de pastagens degradadas.

Os resultados do mapeamento indicaram que, no ano de $2019,63,70 \%$ das áreas de pastagens na Sub-bacia do Ribeirão Douradinho apresentaram grau de degradação baixo a moderado, com valores médios de NDVI inferiores a 0,43. Em contrapartida, os outros $36,30 \%$ das áreas de estudo apresentam pastagens melhoradas, sem indícios de degradação, com valores de NDVI superiores a 0,43. Esses resultados estão de acordo com aqueles obtidos por outros autores, os quais afirmam que mais de $60 \%$ das pastagens do Bioma Cerrado apresentam indício de degradação.

Diante dos resultados obtidos, é possível afirmar que os dados Sentinel 2/MSI são adequados para o mapeamento de pastagem e qualidade em pastagem. Além de serem disponibilizados gratuitamente, sua boa resolução espacial (10 metros), possibilitam a geração de Índices de Vegetação de alta qualidade que revolucionam esse tipo de mapeamento. No entanto, são necessários mais estudos, utilizando outros índices (como o Índice de Vegetação Ajustado ao Solo - SAVI), para buscar atingir melhores resultados de acurácia. 


\section{REFERÊNCIAS}

AB'SÁBER, A. N. Os domínios de natureza no Brasil: potencialidades paisagísticas. São Paulo: Ateliê Editorial, 2003.

ADDABBO, P. et al. Contribution of Sentinel-2 data for applications in vegetation monitoring. Acta IMEKO, v. 5, n. 2, p. 44-54, sept. 2016.

ANJOS, V. S. et al. Caracterização espectro-temporal de pastagens do Triângulo Mineiro utilizando dados MODIS EVI2 (2000-2010). Sociedade \& Natureza, Uberlândia, v. 25, n.1, p. 205-215, jan./abr. 2013.

BACCARO, C. A. D. Estudo dos processos geomorfológicos de escoamento pluvial em área de cerrado, Uberlândia - MG. 1990. 173 p. Tese (Doutorado em Geografia) Faculdade de Filosofia, Letras e Ciências Humanas, Universidade de São Paulo, São Paulo, SP.

BRASIL. Ministério da Agricultura, Pecuária e Abastecimento. Superintendência Federal de Agricultura de Minas Gerais. Estado da Arte das Pastagens em Minas Gerais. Belo Horizonte: $\quad$ INAES, $2015 . \quad$ Disponível em: http://www. sistemafaemg.org.br/Conteudo.aspx?Code $=9483 \&$ Portal $=4 \&$ ParentCode $=1402 \& P$ arentPath $=$ None $\&$ ContentVersion $=\mathrm{R}$. Acesso em 20 de janeiro de 2020.

BRITO, J. L. S. et al. MODIS estimates of pasture productivity in the Cerrado based on ground and Landsat- 8 data extrapolations. Journal of Applied Remote Sensing, v. 12, n. 2, p. 1-20, apr. 2018.

BRITO, J. L. S. Mapeamento e avaliação da qualidade das pastagens cultivadas no Triângulo Mineiro a partir de imagens Oli/Landsat-8. Revista Caminhos de Geografia, v. 19, n. 67, p. $68-82$, set. $2018 \mathrm{~b}$.

DIAS FILHO, M. B. Degradação de Pastagens: processos, causas e estratégias de recuperação. 4 ed. Belém: MBDF, 2011.

ESA - European Space Agency. Missions. Sentinel 2. 2020. Disponível em: https://sentinel.esa.int/web/sentinel/missions/sentinel-2. Acesso em 02 de abr. de 2020.

FERREIRA, L. G. et al. Biophysical characteristics and fire occurrence of cultivated pastures in the Brazilian savanna observed by moderate resolution satellite data. Remote Sensing, v.5, p. 307-326, sept. 2012.

GARCIA, J. C. Apropriação da Natureza no Município de Uberlândia: Alternativas sustentáveis para o uso da água em assentamentos rurais. Observatorium: Revista Eletrônica de Geografia, v.6, n.17, p. 29-51, out. 2014.

GOOGLE LLC. Google Earth Engine. Earth Engine Code Editor. Disponível em: https://developers.google.com/earth-engine/playground. Acesso em: 25 ago. 2020.

GOMES, D. F. Uso de imagens Sentinel-2 na identificação de áreas com infestação do capim-annoni-2 no Complexo Eólico Cerro Chato, Santana do Livramento, RS. 2017. 77p. Dissertação (Mestrado em Sensoriamento Remoto) - Centro Estadual de Pesquisas em Sensoriamento Remoto e Meteorologia, Universidade Federal do Rio Grande do Sul, Porto Alegre, RS.

IBGE - Instituto Brasileiro de Geografia e Estatística. Geociências. Organização do território. Disponível em: https://www.ibge.goVol.br/geociencias/organizacao-do-territorio.html. Acesso em 4 de abr. de 2020.

IGAM - Instituto Mineiro de Gestão das Águas. Regulação de Uso de Recursos Hídricos. Disponível em: http://portalinfohidro.igam.mg.goVol.br/regulacao-de-usos-de-recursoshidricos. Acesso em: 2 de abr. de 2020. 
INMET - Instituto Nacional de Meteorologia. Banco de Dados Meteorológicos para Ensino e Pesquisa. Uberlândia. $2018 . \quad$ Disponível em: http://www.inmet.goVol.br/portal/index.php?r=bdmep/bdmep. Acesso em: 2 de abr. de 2020.

INPE - Instituto Nacional de Pesquisas Espaciais. Projeto TerraClass Cerrado: Mapeamento do Uso e Cobertura Vegetal do Cerrado. 2013. Disponível em: http://www.dpi.inpe.br/tccerrado/. Acesso em: 4 nov. 2019.

KUCHLER, P. C. et al. Extração de métricas fenológicas a partir de séries temporais de NDVI visando o mapeamento da intensificação sustentável da agricultura brasileira. In: XXVII Congresso Brasileiro de Cartografia e XXVI Exposicarta, 27., 2017, Rio de Janeiro. Anais [...] Rio de Janeiro: SBC, 2017. p. 1582-1586. Disponível em: http://www.cartografia.org.br/cbc/2017/trabalhos/4/fullpaper/CT04-95_1506695788.pdf. Acesso em: 28 out. 2019.

LIU, W. T. H. Aplicações de Sensoriamento Remoto. Campo Grande: Editora UNIDERP, 2007.

LUGASSI, R. et al. Spatial and Temporal Monitoring of Pasture Ecological Quality: Sentinel-2Based Estimation of Crude Protein and Neutral Detergent Fiber Contents. Remote Sensing, 2019, v. 11, n. 7, apr. 2019.

MACEDO, M. C. M.; ZIMMER, A. H. Sistema pasto-lavoura e seus efeitos na produtividade agropecuária. In: FAVORETTO, V. et al. (Ed.). Simpósio Sobre Ecossistema de Pastagens, 2., 1993, Jaboticabal. Anais [...] Jaboticabal: FUNEP, 1993. p. 216-245.

OLIVEIRA, A. P. Dinâmica da comunidade arbórea de formações florestais do bioma cerrado no Triângulo Mineiro. 2011. 113 f. Tese (Doutorado em Ciências Biológicas) Universidade Federal de Uberlândia, Uberlândia, 2011.

PARENTE, L. L.; FERREIRA, L. G. Assessing the Spatial and Occupation Dynamics of the Brazilian Pasturelands Based on the Automated Classification of MODIS Images from 2000 to 2016. Remote Sensing, v. 10, n. 4, p. 1-14, apr. 2018.

PEREIRA, O. J. R. et al. Assessing Pasture Degradation in the Brazilian Cerrado Based on the Analysis of MODIS NDVI Time-Series. Remote Sensing, v. 10, n. 11,p. 1-14, 2018.

PUNALEKAR, S. M. Application of Sentinel-2A data for pasture biomass monitoring using a physically based radiative transfer model. Remote Sensing of Environment, v. 218, p. 207-220, dec. 2018.

ROSA, R. O uso de SIGs para o zoneamento: uma abordagem metodológica. 1995. 225 p. Tese (Doutorado em Geografia Física) - Faculdade de Filosofia, Letras e Ciências Humanas, Universidade de São Paulo, São Paulo, 1995.

ROSA, R. Introdução ao Sensoriamento Remoto. 6 ed. Uberlândia: EDUFU, 2007.

ROUSE, J. W. et al. Monitoring vegetation systems in the Great Plains with ERTS. In: III Symposiun of ETRS. Proceedings [...] Maryland, USA, 1973.

SANO, E. E. et al. Mapeamento semidetalhado do uso da terra do Bioma Cerrado. Pesquisa Agropecuária Brasileira, v.43, n. 1, p.153-156, jan. 2008.

SANO, E. E. et al. Land use dynamics in the Brazilian Cerrado in the period from 2002 to 2013. Pesquisa Agropecuária Brasileira, v. 54, p. 1-5, apr. 2019.

SCARAMUZZA, Carlos Alberto de Mattos. et al. Land-use and land-cover mapping of the Brazilian Cerrado based mainly on landsat- 8 satellite images. Revista Brasileira de Cartografia, v. 69, n. 6, p. 1041-1051, jun. 2017. 
SCHIAVINI, I.; ARAÚJO, G. M. Considerações sobre a vegetação da Reserva Ecológica do Panga (Uberlândia). Sociedade \& Natureza, v. 1, p. 61-66, 1989.

SPAIN, J. M.; GUALDRÓN, R. Degradación y rehabilitación de pasturas. In: IV Reunión del Comité Asesor de la Riept. Memórias. Red internacional de evaluación de pastos tropicales. Veracruz: CIAT,1988. p. 269-283.

SILVA, J. F. et al. Spatial heterogeneity, land use and conservation in the cerrado region of Brazil. Journal of Biogeography, v. 33, p. 536-548, 2006.

SILVEIRA, H. L. F. Uso de dados do sensor MSI/Sentinel-2 e de Lidar aerotransportado para mapeamento de fitofisionomias de Caatinga e estudo das relações com atributos físico-químicos dos solos. 2018. 136p. Dissertação (Mestrado em Sensoriamento Remoto) - Instituto Nacional de Ciências Espaciais, MCTIC, São José dos Campos. 